\title{
Breast Milk Jaundice
}

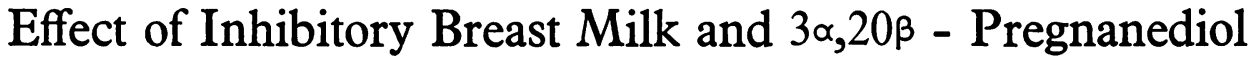 on Glucuronyl Transferase}

\author{
T. HARGREAVES and R. F. PIPER \\ From the Area Pathology Laboratory, Exeter, Devon
}

\begin{abstract}
Hargreaves, T., and Piper, R. F. (1971). Archives of Disease in Childhood, 46, 195. Breast milk jaundice: effect of inhibitory breast milk and $3 \alpha$, $20 \beta$-pregnanediol on glucuronyl transferase. The effect of breast milk and $3 \alpha, 20 \beta$-pregnanediol on the conjugation of bilirubin and $o$-aminophenol by rat liver was compared. Breast milk inhibited glucuronyl transferase, whereas $3 \alpha$, $20 \beta$-pregnanediol inhibited the secretion of bilirubin glucuronide from rat liver slices. In the inhibitory breast milk examined the steroid was probably not the sole inhibitory factor.
\end{abstract}

Unconjugated hyperbilirubinaemia in infants associated with breast milk feeding is not uncommon in paediatric practice. Arias et al. (1964) suggested that jaundice was caused by inhibition of the hepatic glucuronide conjugating mechanism essential for bilirubin excretion. These authors found that milk from mothers nursing jaundiced infants contained $3 \alpha, 20 \beta$-pregnanediol which inhibited conjugation in animal liver slice and homogenate preparations. The steroid produced a rise in serum bilirubin levels when administered to two normal term infants after the period of physiological jaundice (Arias and Gartner, 1964). Recently there has been some evidence that $3 \alpha, 20 \beta$-pregnanediol may not be the causative agent in breast milk jaundice (Adlard and Lathe, 1970). We have examined the effect of breast milk from the mother of a baby who had breast milk jaundice on conjugation mechanisms in rat liver, and compared the results with those obtained by adding $3 \alpha, 20 \beta$ pregnanediol.

\section{Case Report}

A male child, the first of healthy parents, was noted to be jaundiced 28 hours after birth. The pregnancy had been uneventful and the child weighed $3.6 \mathrm{~kg}$ after a normal delivery at term. There was no evidence of haemolytic disease; the mother and baby were group $\mathrm{O}, \mathrm{Rh}$ positive; the infant's direct antiglobulin test was negative. 5 days after birth the total serum bilirubin was $12.8 \mathrm{mg} / 100 \mathrm{ml}$ (conjugated bilirubin

Received 26 August 1970.
$1.6 \mathrm{mg} / 100 \mathrm{ml}$ ) and on the 9th day it was $13.4 \mathrm{mg} /$ $100 \mathrm{ml}$ (conjugated $1.0 \mathrm{mg} / 100 \mathrm{ml}$ ). Serum bilirubin levels on the 18th and 36 th day were $9.2 \mathrm{mg} / 100 \mathrm{ml}$ (conjugated bilirubin $0.8 \mathrm{mg} / 100 \mathrm{ml}$ ) and $6.6 \mathrm{mg} /$ $100 \mathrm{ml}$ (conjugated $0.8 \mathrm{mg} / 100 \mathrm{ml}$ ), respectively.

The child had been fully breast fed throughout, and on the 36th day other foods were added. On the 43rd day the total serum bilirubin was $6.0 \mathrm{mg} / 100 \mathrm{ml}$. Breast feeding was then stopped and the serum bilirubin fell to normal by the 60th day. Breast milk collected on days 5 and 36 was examined for inhibition of bilirubin conjugation using rat liver slices. The milk collected on the 5 th day inhibited bilirubin conjugation by $92 \%$ and that on the 36th day by $100 \%$. Mother's serum collected on the 5 th day gave $13 \%$ inhibition of bilirubin conjugation, which is within normal limits for this time. The investigations confirmed the clinical diagnosis of breast milk jaundice.

Milk collected on the 36 th day was used for subsequent investigations.

Materials and Methods

Male albino Wistar rats weighing 200-250 g were used. Bilirubin conjugation by liver slices was determined from the amount of direct reacting bilirubin in the incubation medium by the method of Lathe and Walker (1958a). The total and conjugated bilirubin content of the liver slices was determined by the method of Hargreaves (1965) with one modification: the bilirubin estimations were performed at $4{ }^{\circ} \mathrm{C}$ throughout.

The rate of bilirubin conjugation in rat liver microsomes was determined by method II of Van Roy and Heirwegh (1968) in the presence of $2.0 \mathrm{mmol}$ UDPGA. $o$-Aminophenol conjugation by rat liver slices was determined using the method of Levvy and Storey (1949) and in rat liver microsomes by the method of 


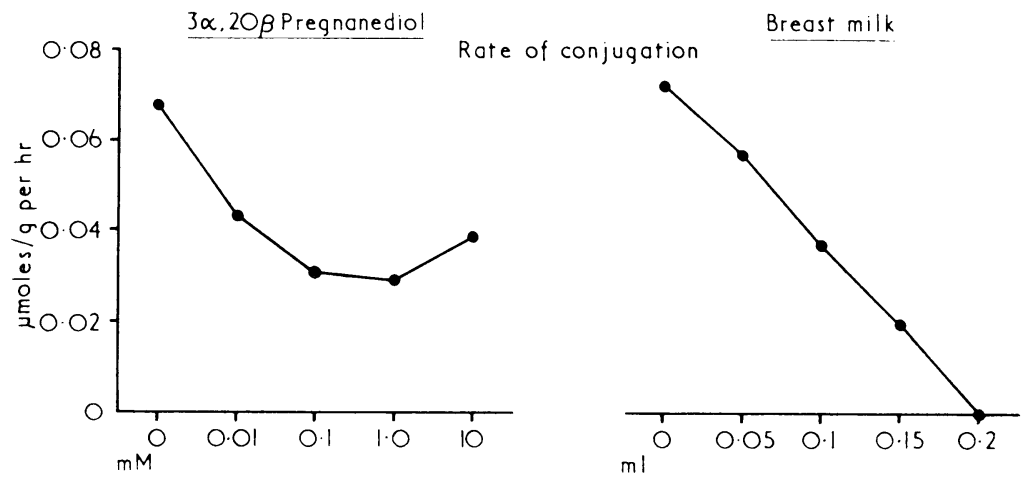

Bilirubin content of slice
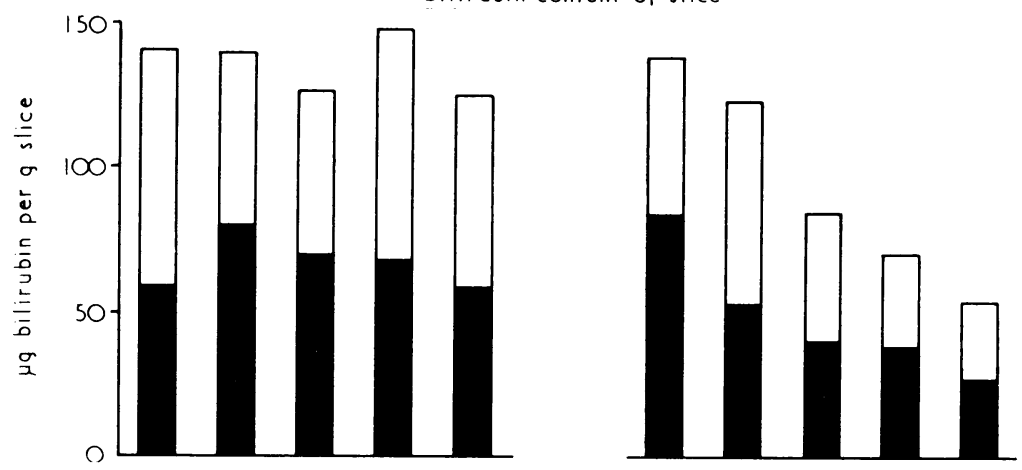

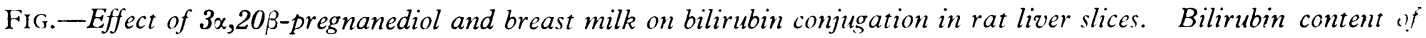
slice: unconjugated $\square$ conjugated

Stevenson and Dutton (1962). 3x,20 $\beta$-pregnanediol and breast milk were added to the incubation flasks and tubes. The steroid was dissolved in ethanol and the solvent evaporated; the final concentrations were 0.01 , $0.1,1.0,10.0 \mathrm{mmol}$. The nature of the residual material was checked by gas liquid chromatography.

The maximum hepatic clearance of bilirubin was determined in male Wistar rats using the method of Weinbren and Billing (1956). 3 $\alpha, 20 \beta$-pregnanediol was dissolved in propan-1 :2-diol and injected intraperitoneally 1 hour before the infusion of bilirubin.

$3 \alpha, 20 \beta$-pregnanediol and uridine 5 -pyrophosphate glucuronic acid (UDPGA) were obtained from Sigma Chemical Co. Ltd; bilirubin and all other reagents from British Drug Houses, Ltd.

\section{Results}

The effect of adding different amounts of the breast milk and $3 \alpha, 20 \beta$-pregnanediol to the rat liver slice conjugating system and determining the amount of conjugated bilirubin in the medium (rate of conjugation) and the amount in the liver slice is shown in the Fig. In liver slices the reactions leading to the synthesis of bilirubin glucuronide can be considered in stages; (1) uptake of bilirubin from the medium; (2) transfer of glucuronic acid to bilirubin which is catalysed by a microsomal enzyme glucuronyl transferase (UDP glucuronate transferase (acceptor unspecific) EC 2.1.4.17); (3) excretion of bilirubin glucuronide from the liver cell to the medium. If there is inhibition of glucuronyl transferase than the amount of conjugated bilirubin in the medium and in the slice is decreased. The addition of breast milk from the mother of a child with breast milk jaundice decreased the rate of bilirubin conjugation by rat liver slices, and also the amount of conjugated bilirubin in the slice, suggesting inhibition of glucuronyl transferase. Addition of up to $10 \mathrm{mmol} 3 \alpha, 20 \beta$ pregnanediol to rat liver slices conjugating bilirubin decreased the rate of conjugation to less than $50^{\prime \prime}$ " of the control value, but it did not reduce the amount of conjugated bilirubin in the slice. Complete inhibition of bilirubin conjugation could not be achieved though this degree of inhibition was found using inhibitory breast milk. Similar results were obtained by suspending the steroid in 
non-inhibitory breast milk and adding it to the conjugating system in concentrations up to $10 \mathrm{mg}$ steroid per ml breast milk.

The addition of breast milk to rat liver slices conjugating $o$-aminophenol decreased the rate of conjugation, whereas addition of $3 \alpha, 20 \beta$-pregnanediol had no effect (Table I).

\section{TABLE I}

Effect of Inhibitory Breast Milk and $3 \alpha, 20 \beta-$ pregnanediol on o-aminophenol Conjugation by Rat Liver Slices

\begin{tabular}{c|c|c|c}
\hline $\begin{array}{c}\text { Breast Milk } \\
\text { (ml) }\end{array}$ & $\begin{array}{c}\text { Rate of } \\
\text { Conjugation }\end{array}$ & $\begin{array}{c}\text { Concn (m mol) } \\
3 \alpha, 20 \beta \text {-pregnanediol }\end{array}$ & $\begin{array}{c}\text { Rate of } \\
\text { Conjugation }\end{array}$ \\
\hline 0.0 & 0.55 & 0.0 & 0.55 \\
0.05 & 0.47 & 0.01 & 0.58 \\
0.1 & 0.34 & 0.1 & 0.55 \\
0.15 & 0.22 & 1.0 & 0.50 \\
0.2 & 0.12 & 10.0 & 0.51 \\
\hline
\end{tabular}

The mean rate of $o$-aminophenol conjugation is expressed as $\mu$ mole/g wet wt per $\mathrm{hr}$, and is the mean of 3 experiments.

The transferase stage of conjugation was examined in rat liver microsomes using bilirubin or $o$-aminophenol as substrates and adding UDPGA. The addition of breast milk decreased the amount of bilirubin (Table II) and $o$-aminophenol glucuronide (Table III) formed by rat liver microsomes under these conditions. Addition of $3 \alpha, 20 \beta$-pregnanediol did not decrease the rate of conjugation of these substrates.

\section{TABLE II}

Effect of Inhibitory Breast Milk and $3 \alpha, 20 \beta-$ pregnanediol on Bilirubin Conjugation by Rat Liver Microsomes

\begin{tabular}{c|c|c|c}
\hline $\begin{array}{c}\% \\
\text { Breast Milk }\end{array}$ & $\begin{array}{c}\text { Rate of } \\
\text { Conjugation }\end{array}$ & $\begin{array}{c}\text { Concn (m mol) } \\
3 x, 20 \beta \text {-pregnanediol }\end{array}$ & $\begin{array}{c}\text { Rate of } \\
\text { Conjugation }\end{array}$ \\
\hline 0.0 & 0.62 & 0.0 & 0.46 \\
2.5 & 0.46 & 0.01 & 0.46 \\
5.0 & 0.35 & 0.1 & 0.46 \\
7.5 & 0.23 & 1.0 & 0.46 \\
10.0 & 0.16 & 10.0 & 0.46 \\
\hline
\end{tabular}

The mean rate of bilirubin conjugation is expressed as $\mu \mathrm{mol} / \mathrm{g}$ wet wt per hr and is the mean of 3 experiments.

The effect of $3 \alpha, 20 \beta$-pregnanediol on the maximum hepatic transport of bilirubin was determined. Infusion of bilirubin into 18 control rats gave a mean value for the maximum hepatic transport of bilirubin of $81.5 \mu \mathrm{g}$ bilirubin/100 $\mathrm{g}$ body wt per hr. 5 rats were given an intraperitoneal injection of $11 \mathrm{mg} / 100 \mathrm{~g}$ body wt. $3 \alpha, 20 \beta$-pregnanediol, and in these rats the mean value of the maximum hepatic
TABLE III

Effect of Inhibitory Breast Milk and $3 \alpha, 20 \beta$ pregnanediol on o-aminophenol Conjugation by Rat Liver Microsomes

\begin{tabular}{c|c|c|c}
$\begin{array}{c}\% \\
\text { Breast Milk }\end{array}$ & $\begin{array}{c}\text { Rate of } \\
\text { Conjugation }\end{array}$ & $\begin{array}{c}\text { Concn (m mol) } \\
\text { 3.x, 20ß-pregnanediol }\end{array}$ & $\begin{array}{c}\text { Rate of } \\
\text { Conjugation }\end{array}$ \\
\hline 0.0 & 0.67 & 0.0 & 0.31 \\
$2 \cdot 1$ & 0.37 & 0.01 & 0.29 \\
4.2 & 0.21 & 0.1 & 0.30 \\
6.3 & 0.17 & 1.0 & 0.30 \\
& & 10.0 & 0.32 \\
\hline
\end{tabular}

The mean rate of $o$-aminophenol conjugation is expressed as $\mu \mathrm{mol} / \mathrm{g}$ wet wt per $\mathrm{hr}$ and is the mean of 3 experiments.

transport of bilirubin was $75.6 \mu \mathrm{g}$ bilirubin $/ 100 \mathrm{~g}$ body wt. 2 rats were given an intraperitoneal injection of $22 \mathrm{mg} / 100 \mathrm{~g}$ body wt $3 \alpha, 20 \beta$-pregnanediol, and in these the mean maximum hepatic transport of bilirubin was $98.4 \mu \mathrm{g} / 100 \mathrm{~g}$ body $\mathrm{wt} / \mathrm{hr}$.

\section{Discussion}

It has been suggested that breast milk jaundice in infants is due to the presence of $3 \alpha, 20 \beta$-pregnanediol in breast milk (Arias et al., 1964). We have examined the effect of breast milk on in vitro conjugation systems and compared it with the effect of $3 \alpha, 20 \beta$-pregnanediol. Our results show that in the case examined breast milk had a different effect on conjugation from $3 \alpha, 20 \beta$-pregnanediol. Addition of inhibitory breast milk to rat liver slices conjugating bilirubin can cause $100 \%$ inhibition, whereas addition of $3 \alpha, 20 \beta$-pregnanediol only achieves a maximum of $55 \%$ inhibition of bilirubin conjugation when compared with control values. Breast milk decreases the amount of bilirubin in rat liver slices whereas the steroid does not. Bevan, Holton, and Lathe (1965) suggested that $3 \alpha, 20 \beta-$ pregnanediol decreased bilirubin conjugation in rat liver slices by inhibiting the secretion of bilirubin glucuronide from the slice. The experiments reported here support this conclusion, since there is a reduction of conjugated bilirubin in the medium but not in the liver slice, suggesting inhibition of the secretory mechanism. Breast milk decreases the amount of conjugated bilirubin in the liver slices and in the medium, suggesting that glucuronyl transferase is inhibited rather than the secretory process. That the steroid acts on the secretory mechanism for bilirubin glucuronide is also suggested by the observation that it does not inhibit other conjugation systems, whereas breast milk inhibits all conjugation systems tested. Also it might be expected that if $3 \alpha, 20 \beta$-pregnanediol inhibits glucuronyl transferase, then it should decrease the maximum hepatic transport of bilirubin as has been 
shown for novobiocin (Billing, Maggiore, and Cartter, 1963), but it does not do this.

The lack of an inhibitory effect on $o$-aminophenol conjugation by $3 \alpha, 20 \beta$-pregnanediol is similar to results found by other workers. Human sera and the most potent steroids inhibiting bilirubin conjugation did not alter $o$-aminophenol conjugation in rat liver slices (Lathe and Walker, 1958b) neither did $3 \alpha, 20 \beta$-pregnanediol (Bevan et al., 1965).

We have compared the effect of breast milk and $3 \alpha, 20 \beta$-pregnanediol on similar animal preparations. The results suggest that in the inhibitory breast milk examined it is unlikely that the steroid is the inhibitory factor. Breast milk inhibits glucuronyl transferase in rat liver whereas $3 \alpha, 20 \beta$-pregnanediol inhibits the secretion of bilirubin glucuronide from rat liver slices. It is possible however that there is more than one inhibitory substance in breast milk and that this is a complex problem not yet fully understood.

We thank Dr. C. W. Kesson for permission to publish the case history, the South Western Regional Hospital Board for financial assistance, and Mr. J. Barraclough for the gas liquid chromatography analyses.

\section{REFERENCES}

Adlard, B. P. F., and Lathe, G. H. (1970). Breast milk jaundice: effect of $3 \alpha, 20 \beta$-pregnanediol on bilurubin conjugation by human liver. Archives of Disease in Childhood, 45, 186.
Arias, I. M., and Gartner, L. M. (1964). Production of unconjugated hyperbilirubinaemia in full-term new-born infants following administration of pregnane-3 $\alpha, 20 \beta$-diol. Nature (London), 203, 1292.

Arias, I. M., Gartner, L. M., Seifter, S., and Furman, M. (1964). Prolonged neonatal unconjugated hyperbilirubinemia associated with breast feeding and a steroid pregnane-3 $\alpha, 20 \beta$-diol in maternal milk that inhibits glucuronide formation in vitro. fournal of Clinical Investigation, 43, 2037.

Bevan, B. R., Holton, J. B., and Lathe, G. H. (1965). The effect of pregnanediol and pregnanediol glucuronide on bilirubin conjugation by rat liver slices. Clinical Sciences, 29, 353.

Billing, B. H., Maggiore, Q., and Cartter, M. A. (1963). Hepatic transport of bilirubin. Annals of the New York Academy of Science, 111, 319.

Hargreaves, T. (1965). The estimation of bilirubin in liver. Clinica Chimica Acta, 11, 278.

Lathe, G. H., and Walker, M. (1958a). The synthesis of bilirubin glucuronide in animal and human liver. Biochemical fournal, $70,705$.

Lathe, G. H., and Walker, M. (1958b). Inhibition of bilirubin conjugation in rat liver slices by human pregnancy and neonatal serum and steroids. Quarterly fournal of Experimental Physio logy and Cognate Medical Sciences, 43, 257.

Levvy, G. A., and Storey, I. D. E. (1949). The measurement of glucuronide synthesis by tissue preparations. Biochemical fournal, 44, 295.

Stevenson, I. H., and Dutton, G. J. (1962). Glucuronide synthesis in kidney and gastrointestinal tract. Biochemical fournal, 82, 330.

Van Roy, F. P., and Heirwegh, K. P. M. (1968). Determination of bilirubin glucuronide and assay of glucuronyltransferase with bilirubin as acceptor. Biochemical fournal, 107, 507.

Weinbren, K., and Billing, B. H. (1956). Hepatic clearance of bilirubin as an index of cellular function in the regenerating rat liver. British fournal of Experimental Pathology, 37, 199.

Correspondence to Dr. T. Hargreaves, Area Laboratory, Church Lane, Heavitree, Exeter, Devon. 